\title{
Application of MH to Prevent Pre-Harvest Sprouting of Seeds in Groundnut
}

\author{
J. Mishra* and S.K. Swain \\ Department of Seed Science and Technology, College of Agriculture, OUAT, Bhubaneswar, \\ Orissa, Pincode-751003, India \\ *Corresponding author
}

\begin{tabular}{|c|}
\hline Keywords \\
\hline $\begin{array}{l}\text { MH, Pre-harvest } \\
\text { sprouting, Groundnut, } \\
\text { Induction of seed } \\
\text { dormancy }\end{array}$ \\
\hline Article Info \\
\hline $\begin{array}{l}\text { Accepted: } \\
\text { 04 August } 2019 \\
\text { Available Online: } \\
\text { 10 September } 2019\end{array}$ \\
\hline
\end{tabular}

A B S T R A C T
An investigation was undertaken during kharif 2017 at the Central Research Station and Department of Seed Science and Technology, OUAT, Bhubaneswar to find out the optimum dose of foliar application of $\mathrm{MH}$ for inducing seed dormancy in groundnut in order to prevent pre-harvest sprouting of seeds in groundnut. The experimental material consisted of three groundnut varieties namely, TG $37 \mathrm{~A}$, TG 38 B and Devi and six treatments namely, MH @ 0, 250, 500, 750, 1000 and 1250 ppm applied as foliar spray at 70 and 90 DAS. Appropriate agronomic practices were followed for raising the seed crops. Applications of $\mathrm{MH}$ resulted in partial induction of seed dormancy which lasted upto one week in all the three varieties and the extent of dormancy increased with increase in dose of $\mathrm{MH}$. Among the varieties, Devi responded well to dormancy induction treatments followed by TG $38 \mathrm{~B}$ and TG $37 \mathrm{~A}$. The highest seed dormancy was induced with application of MH@1250 ppm with seed germination values of $43.00 \%$ and $59.83 \%$ immediately and after one week of harvest, respectively.

\section{Introduction}

Groundnut (Arachis hypogea L.) is an important crop among oil seeds, as it can be consumed and utilized in diverse ways. Groundnut seeds are rich in oil and protein however, groundnut varieties exhibit a wide variability in their germination behaviour. The cultivated groundnut Arachis hypogaea L. has two sub species: subspecies hypogaea (Virginia Bunch and Virginia Runner varieties) and subspecies fastigiata (Spanish and Valencia varieties). The kernels of
Spanish and Valencia bunch types are usually non-dormant, whereas those of Virginia bunch and runner varieties are dormant (Rao, 1976). The non-dormant character in Spanish and Valencia bunch type is undesirable for its cultivation in summer season. In the country, groundnut is grown as a rainfed crop in the kharif or rainy season.

Seed dormancy is defined as a state in which seeds are prevented from germinating even under environmental condition normally favourable for germination. Seed dormancy is 
an important factor in commercial groundnut production. It can be beneficial when dormancy prevents mature seeds from sprouting before harvest. It can be detrimental when dormancy reduces stand or hampers taking a second crop immediately after harvest. Lack of dormancy in bunch types has been described as an inherent property of seeds and does not primarily depends upon soil conditions. The search for investigation of non-conventional methods of inducing dormancy in bunch types to save the produce and to retain the seed quality against sprouting are of greater importance. For inducing seed dormancy in groundnut a number of methods have been developed, out of which foliar application of maleic hydrazide $(\mathrm{MH})$ at variable concentrations and at different stages of crop growth has been successfully used (Shelar et al., 2014).

Maleic hydrazide, a growth inhibitor has been successfully used to inhibit seed germination and to control sprouting of tubers, roots and bulbs during storage. The key idea in the use of growth regulators is to control some aspects of growth, regulate the balance between source and sink, which is the final analysis results in the higher yield of desired product.

The information on the choice of proper concentrations of $\mathrm{MH}$ and its time of application on the locally available groundnut varieties is lacking. Keeping this in view, an attempt has been made to study the feasibility of inducing seed dormancy with various concentrations of maleic hydrazide in groundnut genotypes viz., Devi, TG $37 \mathrm{~A}$ and TG 38 B. The present investigation "Application of $\mathrm{MH}$ to prevent pre-harvest sprouting of seeds in groundnut" was undertaken with the following objectives.

To standardize the dose of application of $\mathrm{MH}$ in inducing short period of dormancy in groundnut.
To study the differential behaviour of groundnut varieties to various dormancy inducing treatments.

\section{Materials and Methods}

The present investigation entitled "Application of $\mathrm{MH}$ to prevent pre-harvest sprouting of seeds in groundnut" was conducted during Kharif, 2017 in the Department of Seed Science and Technology, OUAT, Bhubaneswar situated at $20^{\circ} 15^{\prime}$ North latitude $85^{\circ} 52^{\prime}$ East longitude.. The whole investigation consisted of both field and laboratory tests. The three varieties (V1- TG $37 \mathrm{~A}$; V2- TG 38 B and V3- Devi were grown in the 6 row plots of size $9 \times 7 \mathrm{~m}^{2}$ with spacing $30 \mathrm{~cm} \times 10 \mathrm{~cm}$. The experiment was laid in factorial randomized block design with three replications. Appropriate seed production technology (Agrawal, 2003) was adopted to raise the seed crops.

\section{Factor A: - Treatments}

$\mathrm{T}_{0}$ : Control (distilled water)

$\mathrm{T}_{1}$ : Maleic hydrazide @ $250 \mathrm{ppm}$

$\mathrm{T}_{2}$ : Maleic hydrazide @ 500 ppm

$\mathrm{T}_{3}$ : Maleic hydrazide @ 750 ppm

$\mathrm{T}_{4}$ : Maleic hydrazide @ 1000 ppm

$\mathrm{T}_{5}$ : Maleic hydrazide @ 1250 ppm

Factor B: - Variety (three)

\section{Foliar application of MH}

There were six treatments involving one chemical, maleic hydrazide with spray solution of different concentrations along with a control. The chemical is a growth and respiratory inhibitor. $0.25 \mathrm{~g}, 0.5 \mathrm{~g}, 0.75 \mathrm{~g}, 1 \mathrm{~g}$, $1.25 \mathrm{~g}$ of the chemical was dissolved in 1 litre of distilled water to prepare a solution of 250 ppm, 500 ppm, 750 ppm, 1000 ppm, 1250 ppm concentrations, respectively. Initially 250 ppm of MH spray solution was prepared by 
adding $250 \mathrm{mg}$ of $\mathrm{MH}$ powder in one litre of distilled water. Then mixture was solubilized by using $\mathrm{KOH}$ pellets with the help of magnetic stirrer. Similarly, the spray solution of $500 \mathrm{ppm}, 750 \mathrm{ppm}, 1000 \mathrm{ppm}$ and 1250 ppm were prepared. Care was taken while spraying to prevent the carryover of the drift of solution to the adjoining plots. Maleic hydrazide was sprayed at two stages of crop growth i.e. 70 and 90 DAS. In case of control $\left(\mathrm{T}_{0}\right)$, only distilled water was used for foliar spray.

\section{Seed dormancy}

The degree of induced dormancy in seeds of different varieties receiving $\mathrm{MH}$ treatments was assessed on the basis of percentage of seed germination. Groundnut seeds possessing less than $70 \%$ (IMSCS) germination values were considered to be dormant. The period/ duration of dormancy was calculated as number of days after harvest to attain seed germination equals to minimum certification standards (70\%). The percentage germination was determined at 7 days interval from the days after harvest. Initial germination was recorded on very first day after harvest. Four replicates of 100 seeds from each treatment were sown in between two layers of moist kraft paper, which were again covered by another layer of non-absorbent, wax paper. The entire set was rolled, labelled and kept inside the germinator in upright position. The test conditions of $25 \pm 20^{\circ} \mathrm{C}$ and $95 \pm 2 \% \mathrm{RH}$ were maintained in the germinator. At the end of the tenth day, the number of the normal seedling (seedlings showing normal root and shoot development) were counted and the mean was expressed in percentage (ISTA rules, 1999).

\section{Seedling length}

From the standard germination test, 10 normal seedlings were randomly selected and the seedling length from the root tip to the shoot tip was measured by help of one meter scale and expressed in centimetres.

\section{Seedling dry weight}

The ten normal seedlings selected for seedling length measurement were also used for measuring the seedling dry weight. After removal of the cotyledons, the seedlings were dried in an air oven at $80^{\circ} \mathrm{C}$ for $24 \mathrm{hrs}$.

Weight of the oven-dried seedlings was taken in an electronic balance and mean dry weight of seedling was expressed in grams.

\section{Seed vigour}

The seed vigour was assessed in terms of seed vigour index (SVI) using the observation data of mean seedling length and dry weight as per the following formula. (Abdul-Baki and Anderson, 1973).

SVI-I $=$ Seed germination $(\%) \times$ Mean seedling length $(\mathrm{cm})$

SVI-II $=$ Seed germination $(\%) \times$ Mean seedling dry weight $(\mathrm{g})$

\section{Results and Discussion}

Pre-harvest sprouting of pods due to untimely rain is a serious factor of yield losses in most of the non-dormant groundnut varieties. The problem could be overcome either by growing dormant varieties or by inducing short period of dormancy in the non-dormant varieties by foliar application of chemicals.

The present investigation has been planned to induce dormancy in groundnut seeds by application of various concentrations of $\mathrm{MH}$. The results obtained on different experiments are presented in this chapter under different heads. 


\section{Effect of MH applications on dormancy induction}

\section{Germination percentage}

The extent of induced dormancy in the seeds of different groundnut varieties receiving $\mathrm{MH}$ treatments have been estimated from the weekly germination test results conducted after harvest of the crop. Groundnut seeds showing germination below the certification standards $(70 \%)$ are considered to be dormant and the period of dormancy was measured as the days taken from harvest to achieve $70 \%$ seed germination. The mean values of germination (\%) of different varieties receiving different $\mathrm{MH}$ treatments are presented in Table 1. The results indicated presence of significant variation among treatments at all the stages of study except 21 days after harvest.

The varieties showed significant variation only at the initial stages ( 0 days). The significantly highest germination was recorded in control seed sample (without $\mathrm{MH}$ applications) at all the periods of testing except 21 days after harvest irrespective of genotype/variety. There was a gradual decrease in seed germination percentage with increase in dosage of MH application.

In control $\left(\mathrm{T}_{0}\right)$ the seed germination was $73.58 \%$ at 0 days after harvest which gradually increased to $77.17 \%$ at 7 days after harvest, $83.50 \%$ at 14 days after harvest and $95.00 \%$ at 21 days after harvest. In treatment $\left(\mathrm{T}_{1}\right)$ with application of $250 \mathrm{ppm} \mathrm{MH}$, the germination values were $67.17 \%, 74.33 \%$, $82.25 \%$ and $93.67 \%$ at 0 days, 7 days, 14 days and 21 days after harvest respectively. In treatment $\left(\mathrm{T}_{2}\right)$ with application of $500 \mathrm{ppm}$ $\mathrm{MH}$, the germination values were $61.50 \%$, $66.33 \%, 78.33 \%$ and $95.33 \%$ at 0 days, 7 days, 14 days and 21 days after harvest respectively. In treatment $\left(\mathrm{T}_{3}\right)$ with application of $750 \mathrm{ppm} \mathrm{MH}$, the germination values were $50.67 \%, 63.27 \%, 75.33 \%$ and $93.67 \%$ at 0 days, 7 days, 14 days and 21 days after harvest respectively. In treatment $\left(\mathrm{T}_{4}\right)$ with application of $1000 \mathrm{ppm} \mathrm{MH}$, the germination values were $47.33 \%, 60.00 \%, 72.67 \%$ and $92.67 \%$ at 0 days, 7 days, 14 days and 21 days after harvest respectively. In treatment $\left(\mathrm{T}_{5}\right)$ with application of $1250 \mathrm{ppm} \mathrm{MH}$, the germination values were $43.00 \%, 59.83 \%, 71.50 \%$ and $93.33 \%$ at 0 days, 7 days, 14 days and 21 days after harvest respectively.

The results indicated induction of seed dormancy in variable degrees due to application of MH. Similarly, the degrees of dormancy increased with increase in dose of $\mathrm{MH}$ application. The dormancy also persisted for one week after which the seed germination percentage increased over the certification standards $(70 \%)$ in all the treatments. Among the varieties studied, the groundnut variety Devi, exhibited maximum effect in respect of dormancy induction in comparison to other two varieties. There is positive influence of $\mathrm{MH}$ applications on yield enhancement in this crop.

The results indicated significant variation for this character among the varieties only after harvest and among treatments at 0,7 and 14 days after harvest. However, the interaction effects were found to be non-significant. The mean germination percentage of freshly harvested seeds ranged from $54.33 \%$ (Devi) to $59.79 \%$ (TG 37 A). Among the treatments, the germination percentage was above certification standard $(73.58 \%)$ only in control and ranged between $43.00 \%\left(\mathrm{~T}_{5}\right)$ to $67.17 \%$ $\left(\mathrm{T}_{1}\right)$. The germination percentage decreased with corresponding increase in the concentration of MH applications.

After one week, the germination was increased above the MSCS in $\mathrm{T}_{0}$ and $\mathrm{T}_{1}$ while, the rest of the treatments exhibited 
germination below $70 \%$. There was no significant variation among the varieties. After 2 weeks, the seed germination was increased above the certification standards in all the treatments. However, the treatment showed significant variation with the lowest germination of $71.50 \%$ in $\mathrm{T}_{5}$ and $83.50 \%$ in $\mathrm{T}_{0}$. After 3 weeks, the germination was increased above $90 \%$ in all the treatments.

Thus, from the above results it was found that low to moderate degree of dormancy could be induced in groundnut seeds for a period of one week by foliar application of MH @ 500-1250 ppm and all the three varieties included in the study responded equally to $\mathrm{MH}$ application. Earlier works revealed that the application of an inhibitor $\mathrm{MH}$ could bring about certain changes in the physiological and biochemical processes which are responsible to make the seed dormant by way of arresting the growth of embryo (Khan, 1977 and Bewley and Black, 1982).

It was further reported that the non-dormant nature of bunch groundnut was due to the presence of water soluble auxin (Shreeramalu and Rao, 1971 and Ketring, 1977). Since, MH is an auxin-antagonist, the primary effect of $\mathrm{MH}$ on inducing dormancy seems to be through interference in the tryptophan metabolism, which is the precursor for synthesis of auxin (Karivaratharaju and Rao, 1972).

Dormancy induction in groundnut by application of $\mathrm{MH}$ with variable doses has been reported by several other workers (Nagarjun et al., 1980; Gupta et al., 1985; Bhapkar et al., 1986; Abrar and Jadhav, 1991; Nautiyal, 2004; Jaydeva, 2008 and Sudha rani et al., 2013). Although, MH @ 250 ppm was reported inducing seed dormancy for a period of 10-20 days in groundnut (Jagatap, 2000) the present investigation, did not agree with this result.

\section{Seedling length}

The mean seedling length values of different varieties receiving different treatments are presented in Table 2. The results indicated absence of significant variation among varieties, treatments and interaction effects at all the 4 stages of study.

\section{Seedling dry weight}

The mean seedling dry weight values of different varieties receiving different treatments are presented in Table 3.

The results indicated absence of significant variation among varieties, treatments and interaction effects at all the 4 stages of study. The results indicated slight reduction in seedling dry weight values due to application of $\mathrm{MH}$ at 7, 14 and 21 days after harvest, respectively.

\section{Seedling vigour}

\section{Seedling vigour index I (SVI-I)}

The mean values of seedling vigour indices measured on length basis (SVI-I) among different varieties receiving various $\mathrm{MH}$ treatments are presented in Table 4. The results indicated absence of significant variation among varieties at all the stages except at 21 days after harvest. On the other hand, the treatment effects were significant at all the stages except 21 days and the interaction effects were non-significant at all the stages.

The initial SVI-I values of the varieties ranged from 1088.09 (Devi) to 1227.38 (TG 37 A). After 21 days of harvest, the groundnut variety TG $37 \mathrm{~A}\left(\mathrm{~V}_{1}\right)$, showed the maximum vigour (1950.49) followed by TG $38 \mathrm{~B}\left(\mathrm{~V}_{2}\right)$, with SVI-I value of 1908.42 and Devi $\left(\mathrm{V}_{3}\right)$ with SVI-I value of 1847.33 . 
Table.3 Effect of foliar application of $\mathrm{MH}$ on mean seedling dry weight $(\mathrm{g})$ at weekly intervals after harvest

\begin{tabular}{|c|c|c|c|c|c|c|c|c|c|c|c|c|c|c|c|c|}
\hline \multirow[t]{3}{*}{ Variety/ Treatment } & \multicolumn{16}{|c|}{ Days after harvest } \\
\hline & \multicolumn{4}{|c|}{$\mathbf{0}$} & \multicolumn{4}{|c|}{7} & \multicolumn{4}{|c|}{14} & \multicolumn{4}{|c|}{21} \\
\hline & $\mathbf{V}_{1}$ & $\mathbf{V}_{2}$ & $\mathbf{V}_{3}$ & Mean & $\mathbf{V}_{1}$ & $\mathbf{V}_{2}$ & $\mathbf{V}_{3}$ & Mean & $\mathbf{V}_{1}$ & $\mathbf{V}_{2}$ & $\mathbf{V}_{3}$ & Mean & $V_{1}$ & $\mathbf{V}_{2}$ & $\mathbf{V}_{3}$ & Mean \\
\hline $\mathbf{T}_{\mathbf{0}}$ (Control) & 2.265 & 2.230 & 2.290 & 2.262 & 2.398 & 2.310 & 2.280 & 2.329 & 2.390 & 2.300 & 2.290 & 2.327 & 2.305 & 2.200 & 2.410 & 2.305 \\
\hline$T_{1}(250$ ppm $)$ & 2.250 & 2.300 & 2.270 & 2.273 & 2.270 & 2.270 & 2.260 & 2.267 & 2.240 & 2.280 & 2.270 & 2.263 & 2.310 & 2.290 & 2.310 & 2.303 \\
\hline$T_{2}(500$ ppm $)$ & 2.190 & 2.190 & 2.190 & 2.190 & 2.250 & 2.280 & 2.250 & 2.260 & 2.330 & 2.250 & 2.190 & 2.257 & 2.290 & 2.340 & 2.250 & 2.293 \\
\hline$T_{3}(750$ ppm) & 2.220 & 2.210 & 2.230 & 2.220 & 2.230 & 2.300 & 2.240 & 2.257 & 2.250 & 2.270 & 2.230 & 2.250 & 2.270 & 2.260 & 2.290 & 2.273 \\
\hline $\mathrm{T}_{4}(1000 \mathrm{ppm})$ & 2.230 & 2.240 & 2.240 & 2.237 & 2.250 & 2.290 & 2.210 & 2.250 & 2.240 & 2.250 & 2.250 & 2.247 & 2.260 & 2.240 & 2.260 & 2.253 \\
\hline$T_{5}(1250 \mathrm{ppm})$ & 2.210 & 2.230 & 2.190 & 2.210 & 2.240 & 2.230 & 2.250 & 2.240 & 2.210 & 2.190 & 2.230 & 2.210 & 2.230 & 2.180 & 1.980 & 2.130 \\
\hline \multirow[t]{2}{*}{ Mean } & 2.228 & 2.233 & 2.235 & 2.232 & 2.273 & 2.280 & 2.248 & 2.267 & 2.277 & 2.257 & 2.243 & 2.259 & 2.278 & 2.252 & 2.250 & 2.260 \\
\hline & \multicolumn{2}{|c|}{ S.E.m ( $( \pm)$} & \multicolumn{2}{|c|}{ CD $(5 \%)$} & \multicolumn{2}{|c|}{ S.E.m ( $( \pm)$} & \multicolumn{2}{|c|}{ CD (5\%) } & \multicolumn{2}{|c|}{ S.E.m ( $( \pm)$} & \multicolumn{2}{|c|}{ CD $(5 \%)$} & \multicolumn{2}{|c|}{ S.E.m ( $( \pm)$} & \multicolumn{2}{|c|}{ CD (5\%) } \\
\hline Variety & \multicolumn{2}{|c|}{0.0315} & \multicolumn{2}{|c|}{ NS } & \multicolumn{2}{|c|}{0.1420} & \multicolumn{2}{|c|}{ NS } & \multicolumn{2}{|c|}{0.0140} & \multicolumn{2}{|c|}{ NS } & \multicolumn{2}{|c|}{0.0320} & \multicolumn{2}{|c|}{ NS } \\
\hline Treatment & \multicolumn{2}{|c|}{0.0446} & \multicolumn{2}{|c|}{ NS } & \multicolumn{2}{|c|}{0.2000} & \multicolumn{2}{|c|}{ NS } & \multicolumn{2}{|c|}{0.0190} & \multicolumn{2}{|c|}{0.0570} & \multicolumn{2}{|c|}{0.0450} & \multicolumn{2}{|c|}{ NS } \\
\hline $\mathbf{V} \times \mathbf{T}$ & \multicolumn{2}{|c|}{0.0772} & \multicolumn{2}{|c|}{ NS } & \multicolumn{2}{|c|}{0.3470} & $N$ & S & 0.0 & 330 & & JS & 0.0 & & & IS \\
\hline
\end{tabular}

$\mathrm{V}_{1}$ : TG $37 \mathrm{~A} ; \mathrm{V}_{2}$ : TG $38 \mathrm{~B} ; \mathrm{V}_{3}$ : Devi

Table.4 Effect of foliar application of MH on seedling vigour index I at weekly intervals after harvest

\begin{tabular}{|c|c|c|c|c|c|c|c|c|c|c|c|c|c|c|c|c|}
\hline \multirow{3}{*}{$\begin{array}{l}\text { Variety/ } \\
\text { Treatment }\end{array}$} & \multicolumn{16}{|c|}{ Days after harvest } \\
\hline & \multicolumn{4}{|c|}{0} & \multicolumn{4}{|c|}{7} & \multicolumn{4}{|c|}{14} & \multicolumn{4}{|c|}{21} \\
\hline & $V_{1}$ & $\mathbf{V}_{2}$ & $\mathbf{V}_{3}$ & Mean & $V_{1}$ & $\mathbf{V}_{2}$ & $\mathbf{V}_{3}$ & Mean & $V_{1}$ & $\mathbf{V}_{2}$ & $\mathbf{V}_{3}$ & Mean & $\mathbf{V}_{1}$ & $\mathbf{V}_{2}$ & $\mathbf{V}_{3}$ & Mean \\
\hline $\mathbf{T}_{0}($ Control) & 1601.98 & 1499.11 & 1428.98 & 1510.02 & 1706.10 & 1660.98 & 1561.67 & 1642.92 & 1725.66 & 1707.72 & 1672.81 & 1702.06 & 1999.17 & 1956.46 & 1806.79 & 1920.81 \\
\hline$T_{1}(250 \mathrm{ppm})$ & 1417.46 & 1332.04 & 1315.80 & 1355.10 & 1557.18 & 1500.35 & 1489.28 & 1515.60 & 1765.94 & 1676.43 & 1640.82 & 1694.39 & 2007.78 & 1868.56 & 1838.44 & 1904.93 \\
\hline$T_{2}(500 \mathrm{ppm})$ & 1261.30 & 1289.50 & 1198.61 & 1249.80 & 1401.69 & 1336.41 & 1297.82 & 1345.31 & 1579.21 & 1551.98 & 1628.50 & 1586.56 & 1887.89 & 1973.16 & 1920.43 & 1927.16 \\
\hline$T_{3}(750 \mathrm{ppm})$ & 1093.40 & 1059.75 & 960.00 & 1037.72 & 1321.50 & 1298.88 & 1247.32 & 1289.23 & 1548.23 & 1513.31 & 1551.52 & 1537.69 & 1918.79 & 1901.67 & 1860.68 & 1893.71 \\
\hline$T_{4}(1000 \mathrm{ppm})$ & 1036.28 & 979.86 & 825.93 & 947.36 & 1263.44 & 1232.83 & 1188.86 & 1228.38 & 1473.47 & 1510.80 & 1510.33 & 1498.20 & 1973.33 & 1839.30 & 1831.64 & 1881.42 \\
\hline$T_{5}(1250 \mathrm{ppm})$ & 953.88 & 888.40 & 799.20 & 880.49 & 1179.66 & 1150.35 & 1237.80 & 1189.27 & 1477.62 & 1425.27 & 1456.55 & 1453.15 & 1915.95 & 1911.36 & 1825.98 & 1884.43 \\
\hline \multirow[t]{2}{*}{ Mean } & 1227.38 & 1174.78 & 1088.09 & 1163.42 & 1404.93 & 1363.30 & 1337.12 & 1368.45 & 1595.02 & 1564.25 & 1576.75 & 1578.67 & 1950.49 & 1908.42 & 1847.33 & 1902.08 \\
\hline & \multicolumn{2}{|c|}{ S.E.m $( \pm)$} & \multicolumn{2}{|c|}{ CD $(5 \%)$} & \multicolumn{2}{|c|}{ S.E.m $( \pm)$} & \multicolumn{2}{|c|}{ CD $(5 \%)$} & \multicolumn{2}{|c|}{ S.E.m $( \pm)$} & \multicolumn{2}{|c|}{ CD $(5 \%)$} & \multicolumn{2}{|c|}{ S.E.m $( \pm)$} & \multicolumn{2}{|c|}{ CD $(5 \%)$} \\
\hline Variety & \multicolumn{2}{|c|}{49.616} & \multicolumn{2}{|c|}{ NS } & \multicolumn{2}{|c|}{21.094} & \multicolumn{2}{|c|}{ NS } & \multicolumn{2}{|c|}{26.417} & \multicolumn{2}{|c|}{ NS } & \multicolumn{2}{|c|}{27.081} & \multicolumn{2}{|c|}{80.803} \\
\hline Treatment & \multicolumn{2}{|c|}{70.168} & \multicolumn{2}{|c|}{209.362} & \multirow{2}{*}{\multicolumn{2}{|c|}{$\begin{array}{l}29.831 \\
51.669\end{array}$}} & \multicolumn{2}{|c|}{89.009} & \multicolumn{2}{|c|}{37.360} & \multicolumn{2}{|c|}{111.471} & \multicolumn{2}{|c|}{38.298} & \multicolumn{2}{|c|}{ NS } \\
\hline $\mathbf{V} \times \mathbf{T}$ & \multicolumn{2}{|c|}{121.535} & \multicolumn{2}{|c|}{ NS } & & & & & 64. & & & & & & & IS \\
\hline
\end{tabular}

$\mathrm{V}_{1}$ : TG 37 A; $\mathrm{V}_{2}$ : TG 38 B; $\mathrm{V}_{3}$ : Devi 
Table.5 Effect of foliar application of $\mathrm{MH}$ on seedling vigour index II at weekly intervals after harvest

\begin{tabular}{|c|c|c|c|c|c|c|c|c|c|c|c|c|c|c|c|c|}
\hline \multirow[t]{3}{*}{ Variety/ Treatment } & \multicolumn{16}{|c|}{ Days after harvest } \\
\hline & \multicolumn{4}{|c|}{$\mathbf{0}$} & \multicolumn{4}{|c|}{7} & \multicolumn{4}{|c|}{14} & \multicolumn{4}{|c|}{21} \\
\hline & $V_{1}$ & $\mathbf{V}_{2}$ & $\mathbf{V}_{3}$ & Mean & $\mathbf{V}_{1}$ & $\mathbf{V}_{2}$ & $\mathbf{V}_{3}$ & Mean & $\mathbf{V}_{1}$ & $\mathbf{V}_{2}$ & $\mathbf{V}_{3}$ & Mean & $V_{1}$ & $\mathbf{V}_{2}$ & $\mathbf{V}_{3}$ & Mean \\
\hline $\mathbf{T}_{0}($ Control $)$ & 173.77 & 162.76 & 162.35 & 166.29 & 192.90 & 177.99 & 171.12 & 180.67 & 204.38 & 192.03 & 186.62 & 194.34 & 223.59 & 215.57 & 216.54 & 218.57 \\
\hline$T_{1}(250$ ppm $)$ & 154.04 & 154.11 & 149.78 & 152.64 & 170.70 & 168.08 & 167.36 & 168.71 & 189.30 & 186.28 & 182.83 & 186.14 & 224.19 & 210.67 & 212.44 & 215.77 \\
\hline$T_{2}(500 \mathrm{ppm})$ & 136.73 & 135.48 & 131.34 & 134.52 & 151.80 & 151.87 & 146.57 & 150.08 & 183.99 & 175.47 & 170.88 & 176.78 & 217.85 & 219.66 & 218.31 & 218.61 \\
\hline$T_{3}(750$ ppm $)$ & 117.71 & 112.76 & 107.04 & 112.50 & 143.04 & 146.74 & 138.95 & 142.91 & 172.10 & 171.34 & 165.04 & 169.49 & 213.53 & 210.08 & 215.02 & 212.88 \\
\hline$T_{4}(1000 \mathrm{ppm})$ & 115.93 & 107.52 & 94.02 & 105.82 & 137.39 & 137.45 & 130.31 & 135.05 & 163.54 & 164.33 & 161.92 & 163.26 & 210.12 & 206.08 & 210.20 & 208.80 \\
\hline$T_{5}(1250 \mathrm{ppm})$ & 101.70 & 98.17 & 83.73 & 94.53 & 133.45 & 130.70 & 138.00 & 134.05 & 160.30 & 157.76 & 156.04 & 158.03 & 205.08 & 207.20 & 185.40 & 199.23 \\
\hline \multirow[t]{2}{*}{ Mean } & 133.31 & 128.47 & 121.38 & 127.72 & 154.88 & 152.14 & 148.72 & 151.91 & 178.93 & 174.53 & 170.56 & 174.67 & 215.73 & 211.54 & 209.65 & 212.31 \\
\hline & \multicolumn{2}{|c|}{ S.E.m ( \pm$)$} & \multicolumn{2}{|c|}{ CD $(5 \%)$} & \multicolumn{2}{|c|}{ S.E.m ( $( \pm)$} & \multicolumn{2}{|c|}{ CD $(5 \%)$} & \multicolumn{2}{|c|}{ S.E.m ( $( \pm)$} & \multicolumn{2}{|c|}{ CD $(5 \%)$} & \multicolumn{2}{|c|}{ S.E.m ( \pm$)$} & \multicolumn{2}{|c|}{ CD (5\%) } \\
\hline Variety & \multicolumn{2}{|c|}{1.547} & \multicolumn{2}{|c|}{4.616} & \multicolumn{2}{|c|}{1.452} & \multicolumn{2}{|c|}{4.332} & \multicolumn{2}{|c|}{1.937} & \multicolumn{2}{|c|}{5.780} & \multicolumn{2}{|c|}{4.272} & \multicolumn{2}{|c|}{ NS } \\
\hline Treatment & \multicolumn{2}{|c|}{2.188} & \multicolumn{2}{|c|}{6.528} & \multicolumn{2}{|c|}{2.053} & \multicolumn{2}{|c|}{6.127} & \multicolumn{2}{|c|}{2.740} & \multicolumn{2}{|c|}{8.175} & \multicolumn{2}{|c|}{6.041} & \multicolumn{2}{|c|}{ NS } \\
\hline $\mathbf{V} \times \mathbf{T}$ & \multicolumn{2}{|c|}{3.790} & \multicolumn{2}{|c|}{ NS } & \multicolumn{2}{|c|}{3.556} & 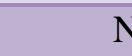 & & 4. & 45 & $\mathrm{~N}$ & S & 10. & & 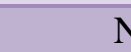 & S \\
\hline
\end{tabular}

$\mathrm{V}_{1}$ : TG $37 \mathrm{~A} ; \mathrm{V}_{2}$ : TG $38 \mathrm{~B} ; \mathrm{V}_{3}$ : Devi 
The mean SVI- I values ranged from 880.49 $\left(\mathrm{T}_{5}\right)$ to $1510.02 \quad\left(\mathrm{~T}_{0}\right)$ indicating gradual decrease in seedling vigour with corresponding increase in the dose of $\mathrm{MH}$ applications. The similar trend in SVI-I values was observed among the treatments after subsequent stages. The decrease in SVI-I values with the application of $\mathrm{MH}$ was due to its antagonistic effect with auxin that restricted seedling growth. Reduction in seedling vigour index and seedling dry weight in groundnut to dormancy induction by application of $\mathrm{MH}$ has also been reported earlier (Jagatap, 2000).

There was also gradual increase in mean seedling vigour values with advancement of periods after harvest. The mean vigour values at harvest were 1163.42 which was increased to 1368.45 then to 1578.68 and 1902.08 at 7 , 14 and 21 days after harvest, respectively.

\section{Seedling vigour index II (SVI II)}

The mean values of seedling vigour measured on dry weight basis (SVI II) among different varieties receiving various $\mathrm{MH}$ treatments are presented in Table 5. There was also gradual increase in mean seedling vigour values with advancement of periods after harvest.

The mean vigour values at harvest was 127.72 which was increased to 151.91 then to 174.67 and 212.31 at 7, 14 and 21 days after harvest, respectively and there was presence of significant variations among the varieties and treatments at 0,7 and 14 days after harvest except at 21 days after harvest while the significant variations among the interactions effects were non-significant at all the stages.

After 21 days of harvest, the groundnut variety TG $37 \mathrm{~A}\left(\mathrm{~V}_{1}\right)$, showed the maximum vigour value of 215.73 followed by TG $38 \mathrm{~B}$ $\left(\mathrm{V}_{2}\right)$, with vigour index value of 211.54 and Devi $\left(V_{3}\right)$ with vigour index value of 209.65 .
Among the treatments, the highest vigour index value was observed in control $\left(\mathrm{T}_{0}\right)$ at all the stages except 21 days after harvest and there was a gradual decrease in seedling vigour indices with increase in concentration of MH except 21 days after harvest.

There was also gradual increase in mean seedling vigour values with advancement of periods after harvest. The mean vigour values at harvest were 127.72 which was increased to 151.91 then to 174.67 and 212.31 at 7, 14 and 21 days after harvest, respectively.

The present investigation was conducted during kharif, 2017 at the Central Research Station and Department of Seed Science and Technology, OUAT, Bhubaneswar to standardize the dose of $\mathrm{MH}$ application for inducing seed dormancy in groundnut. The experiment was laid in factorial RBD with three varieties, six treatments and three replications.

The experimental materials consisted of three groundnut varieties viz., TG 37 A, TG 38 B and Devi and six treatments viz., MH @0 ppm, 250 ppm, 500 ppm, 750 ppm, 1000 ppm and $1250 \mathrm{ppm}$. The recommended package of practices was adopted for raising the seed crop.

Application of $\mathrm{MH}$ resulted in partial induction of seed dormancy upto one week in all the three varieties. The extent of dormancy increased with increase in the dose of $\mathrm{MH}$ application. Immediately after harvest, the lowest seed germination (43.00\%) was observed in $\mathrm{T}_{5}$ followed by $\mathrm{T}_{4}(47.33 \%)$ in comparison to the control (73.58\%). After one week, there was improvement in germination in all the treatments ranging from 59.83\% $\left(\mathrm{T}_{5}\right)$ to $77.17 \%\left(\mathrm{~T}_{0}\right)$. Among the varieties included in the study, Devi exhibited higher dormancy in comparison to others. Besides inducing dormancy, applications of $\mathrm{MH}$ 
resulted in significant reduction in seed vigour (SVI-I and SVI-II) in all the three varieties at the initial stages.

In the present investigation, it is apparent that foliar application of $\mathrm{MH} @ 1000$ ppm to 1250 ppm at 70 and 90 DAS resulted in partial induction of seed dormancy for a period of one week.

\section{Acknowledgement}

I want to express my heartfelt, deep sense of unbound gratitude to Dr. S.K Swain, Professor and Head, Department of Seed Science and Technology, College of Agriculture, OUAT, Bhubaneswar, my Guide and Chairman of Advisory Committee for laying out the guidelines of research work and framing my mind to think systematically and logically and help me to do my research work properly.

\section{References}

Abdul-Baki, A.A. and Anderson, J.G. 1973. Vigour determination in soybean seeds by multiple criteria. Crop Science. 13: 630-633.

Abrar, A.K. and Jadhav, B.B. 1991. Effect of growth regulators, chemicals and temperature on dormancy in peanut. Ann. Plant Physiology. 5(1): 64-69.

Agrawal, R.L. 2003. Seed Technology, Edn. II, Oxford and IBH Pub., pp. 829.

Bewley, J.D. and Black, M. 1982. Physiology and biochemistry of seeds-viability, dormancy and environmental control, Springs Verlog, Berlin, Hedelberg, New York, 2.

Bhapkar, D.G., Patil, P.S. and Patil, V.A. 1986. Dormancy in groundnut- A Review. Journal of Maharashtra agricultural University. 11(1): 68-71.

Gupta, R.K., Singh, S.S. and Verma, M.M. 1985. Introduction of dormancy in groundnut (Arachis hypogea L.) variety T-64 by maleic hydrazide. Indian Journal of Agricultural Research. 19(2): 82-86.

International Seed Testing Association. 1999. International Rules for Seed Testing. Seed Science and Technology. 21: 1288.

Jagatap, P.B. 2000. Physiological maturity and seed dormancy studies in bunch type groundnut (Arachis hypogaea L.). M.Sc. (Agri.) thesis, PGI, MPKV, Rahuri, pp. 1-85.

Jayadeva, B. 2008. Induction of dormancy in summer groundnut (Arachis hypogaea L.). M. Sc. (Agri.) Thesis, Mahatma Phule Krishi Vidyapeeth, Rahuri, Maharastra, India.

Karivartharaju, T.V. and Rao, J.S. 1972. Effect of maleic hydrazide $(\mathrm{MH})$ on inducing dormancy in rice. Madras agricultural Journal. 59: 257-261.

Ketring, D.L. and Morgan, P.W. 1971. Regulation of dormancy in virginia-type peanut seeds. Plant Physiology. 45: 268-273.

Khan, A.A. 1977. The Physiology and biochemical of seed germination. North- Holland Pub, Co. Amersterdam, pp. 26.

Nagarjun, P., Radder, G.D. and Patil, V.C. 1980. Effect of foliar application of maleic hydrazide on seed quality and seedling vigour in bunch groundnut. Seed Research. 8(2): 121-126.

Nautiyal, PC. 2004. Issues related to maintenance of seed viability and regulation of dormancy in groundnut. Groundnut Research in India. Pp. 321338.

Rao, N.G. 1976. Groundnut breeding in India: present status and future strategy. Paper presented at the Workshop cum Seminar of All India Coordinated Research Project on Oilseeds (Kharif crops). pp. 1-51. 
Shelar, V.R., Karjule, A.P. and Jayadeva, B. 2014. Induction of dormancy in groundnut. An Agricultural Review. 35(3): 216-224.
Sudha, M.S., Rao, R.S., Durga, K., Bharathi, V., Bharathi, K. and Reddy, V. 2013. Induction of dormancy in non-dormant varieties of groundnut. Journal on Cereals and Oil Seeds. 4(7): 89-93.

\section{How to cite this article:}

Mishra, J. and Swain, S.K. 2019. Application of MH to Prevent Pre-Harvest Sprouting of Seeds in Groundnut. Int.J.Curr.Microbiol.App.Sci. 8(09): 15-25.

doi: https://doi.org/10.20546/ijcmas.2019.809.003 